\title{
Crystal Structure Directed Catalysis by Aluminium Metal-Organic Framework: Mechanistic Insight into the Role of Coordination of Al Sites and Entrance Size of Catalytic Pocket
}

\author{
Ayan Maity, ${ }^{1 \#}$ Baljeet Singh, ${ }^{1 \#}$ Kshama Sharma, ${ }^{2}$ Subhradip Paul, ${ }^{3}$ P. K. Madhu,,${ }^{1 *}$ and Vivek Polshettiwar ${ }^{1 *}$ \\ ${ }^{1}$ Department of Chemical Sciences, Tata Institute of Fundamental Research (TIFR), Mumbai, India. Email: vivekpol@tifr.res.in, \\ ${ }^{2}$ TIFR Centre for Interdisciplinary Sciences, TIFR Hyderabad, India. Email: madhu@tifr.res.in \\ ${ }^{3}$ Sir Peter Mansfield Imaging Centre, School of Physics \& Astronomy, University of Nottingham, Nottingham, UK. \\ \# equal contribution
}

\begin{abstract}
The use of metal-organic frameworks (MOFs) in the field of catalysis is growing exponentially due to their high surface area and distinctive active sites. In this work, we report a novel understanding of the active sites responsible for the catalytic activity of aluminum trimesate MOFs and their crystal/framework structure dependency. Here, we have studied the nature of the active sites of Al-MOFs with two different framework structures (MIL-100 \& MIL-96). We found that the MOFs with MIL-100 framework structures were highly catalytically active, while the same Al-MOFs with MIL-96 framework structures exhibited poor catalytic activity. This behavior is explained based on the effect of coordinated water molecules on their Brønsted acidity as well as the effect of the coordination of $\mathrm{Al}$ sites, specifically hexacoordinated $\mathrm{Al}^{3+}{ }_{6 \mathrm{c}}$ sites and pentacoordinated $\mathrm{Al}^{3+}{ }_{5 \mathrm{c}}$ sites, on their Lewis acidity. The different entrance sizes of the catalytic pocket of MIL-96 and MIL-100 also played critical roles in their catalytic performance.
\end{abstract}

Metal-organic frameworks (MOFs) have emerged as heterogeneous catalysts for various reactions. ${ }^{1-3}$ Their use is growing exponentially due to their unique catalytic and gas sorption behavior. However, the chemistry behind their unique activity is still not completely understood, and scientists continue to gain a deeper understanding of their active sites. ${ }^{4-8}$ Thus, a detailed study of the various active sites by which MOFs catalyze reactions is crucial for the design of new MOF-based catalysts. In a continuation of our work on heterogeneous catalysis, ${ }^{9-12}$ in this work, we studied the role of crystal structure and textural properties in the catalytic activity of aluminum trimesate metalorganic frameworks (Al-MOFs).

First, we synthesized two different Al-BTC (1,3,5-tricarboxylic acid) MOFs, M100 and M96 with the framework structure, MIL$100(\mathrm{Al}){ }^{13,14}$ and MIL-96 (Al), ${ }^{15,16}$ respectively. The scanning and transmission electron microscopy (SEM \& TEM) images of M100 and M96 indicate the formation of spherical and hexagonal bipyramidal shaped MOFs (Figure 1). The powder X-ray diffraction (PXRD) patterns of M100 and M96 are in agreement with those of the MIL-100 (Al) and MIL-96 (Al), respectively (Figure 2). ${ }^{13-17}$ With regard to textural properties, both exhibited a type-I sorption isotherm (Figure 2) and a pore size distribution in the micropore region of 3 to $12 \AA$ (Figure 2). M100 possesses a Langmuir surface area of $2717 \mathrm{~m}^{2} / \mathrm{g}$, while M96 possesses 1263 $\mathrm{m}^{2} / \mathrm{g}$ (Table 1). FTIR of both the MOFs showed a similar pattern (Figure S1). The absence of a band at approximately 1710-1720 $\mathrm{cm}^{-1}$ indicates the absence of residual BTC ligands, confirming the purity of the MOFs. ${ }^{18}$ TGA analysis (Figure S2) and EDX (Table S1) measurements also confirmed the purity of these MOFs.

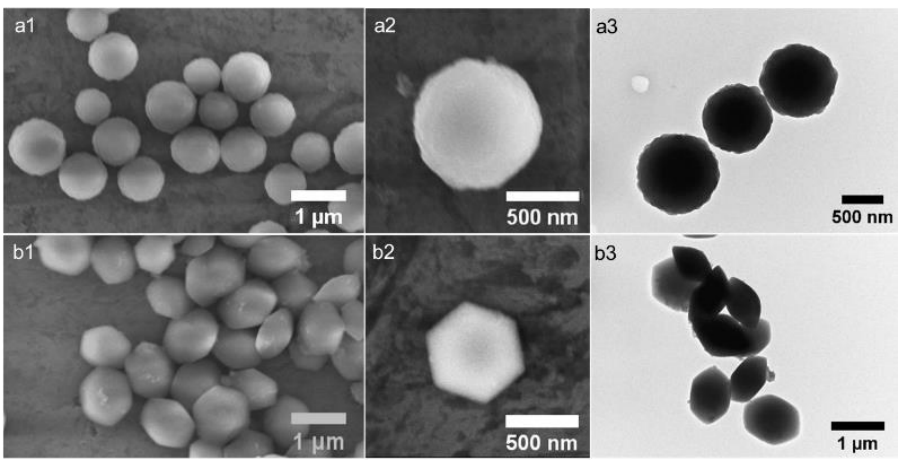

Figure 1. SEM images of (a1, a2) M100, (b1, b2) M96. TEM images of (a3) M100, (b3) M96 Al-MOFs.
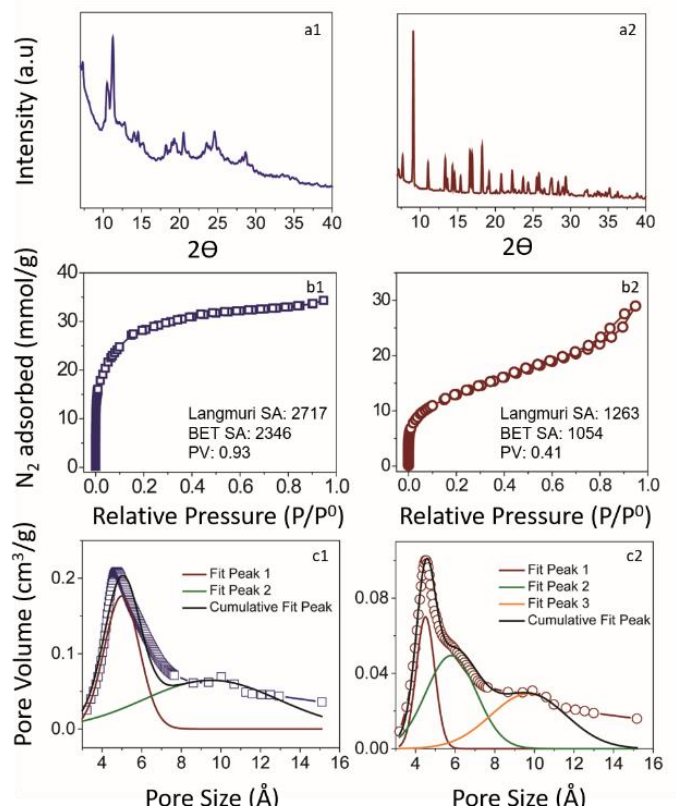

Figure 2. Powder XRD (a1,b1), $\mathrm{N}_{2}$ sorption isotherm (a2,b2), and pore size distribution $(\mathrm{a} 3, \mathrm{~b} 3)$ of M100 and M96 Al-MOFs, respectively. The standard error in surface area $(S A) \pm 4 \%$, in pore volume $(P V) \pm 0.01$. Pore volume was estimated using the Horvath-Kawazoe (HK) method.

To determine the correlations between the MOFs framework structure and textural properties with their catalytic activity, a 
systematic catalytic study was carried out using the acetalization of p-chlorobenzaldehyde as a model reaction (Figure 3 ) which is sensitive to the acidic environment of the active sites. ${ }^{3}$ As these Al-MOFs contain both Brønsted and Lewis acid sites, the acetalization of p-chlorobenzaldehyde (PCB) using methanol will directly probe the acidity behaviors of these MOFs and their dependence on textural properties and framework structure. The relatively larger size of PCB will also allow probing of the role of pore (cavity) size in their diffusion behavior. The M100 exhibited excellent catalytic activity (Figure 3a). On the other hand, the M96 MOF exhibited poor catalytic activity before activation with less than $2 \%$ conversion under exactly the same conditions (Figure 3a, unactivated). Interestingly, catalytic activity after activation at $120{ }^{\circ} \mathrm{C}$ for 4 hours showed slight enhancement in the case of M96 $(\sim 3 \%)$ and a significant decrease was found in the case of M100 ( 58\%) (Figure 3a). The reactant size-dependent catalytic study also showed a decrease in the catalytic activity with the increase in the reactant size (Figure 3b).

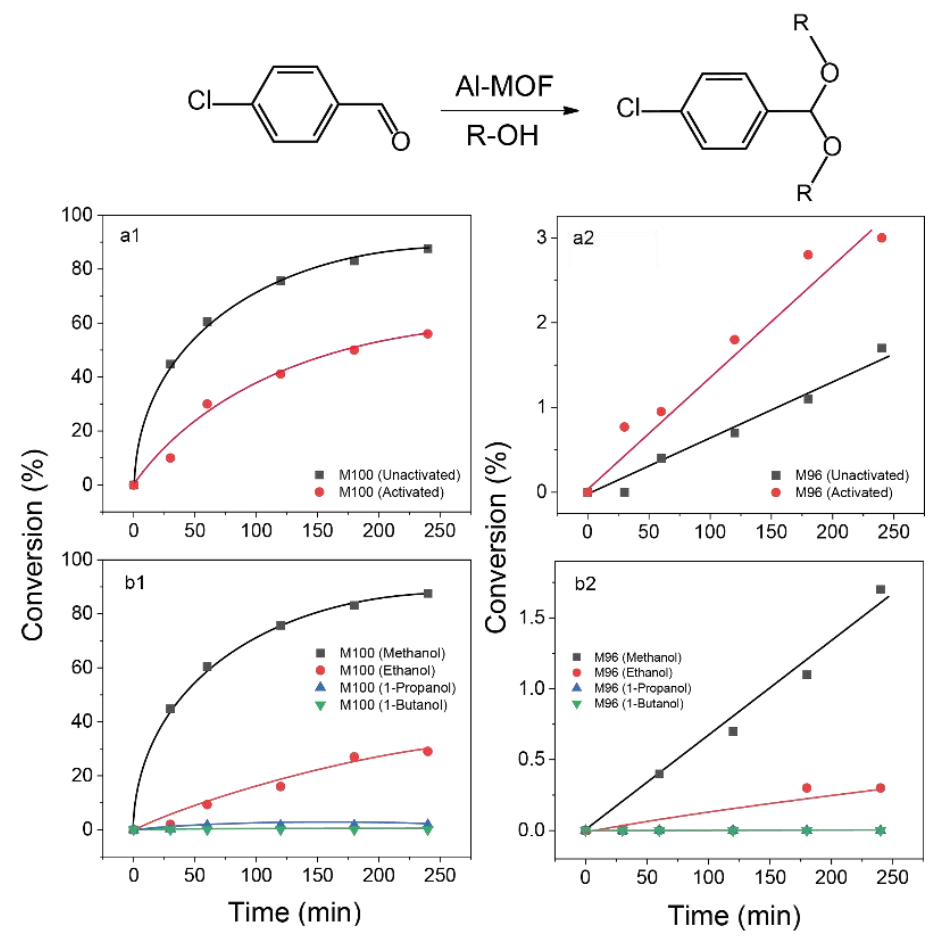

Figure 3. Reaction kinetics of Al-MOF catalyzed acetal formation of pchlorobenzaldehyde by alcohols, a) Methanol is used as the reactant under unactivated and activated condition, b) reactions were carried out by using various alcohols under unactivated condition.

We endeavored to determine the factor that controls the catalytic activity of Al-MOFs. The differences in the catalytic activity of M100 and M96 MOFs could be due to the differences in their textural properties, Lewis $\mathrm{Al}$ sites and Brønsted-coordinated water sites (and their proximal environment) as well as different framework structures. Although, M100 possesses a higher BET surface area $\left(2346 \mathrm{~m}^{2} / \mathrm{g}\right)$ compare to M96 $\left(1054 \mathrm{~m}^{2} / \mathrm{g}\right)$, but this alone cannot explain the significant difference in their catalytic activity (Figure 2b).
The entrance of the cavity of a MOF where the active Lewis and Brønsted Al sites are located (catalytic pocket) will play a critical role in their accessibility and in turn their catalytic performance. The catalytic results (Figure 3 ) indicate the existence of a strong correlation between the cavity entrance size and catalytic activity. From the nitrogen sorption studies (Figure 2) and framework structure analysis (Figure S3, S4), the M100 and M96 exhibit different cavity (pore) sizes. These cavities, particularly their entrance size, will affect the reactant diffusion into the catalytic pocket; hence, we studied the correlation between catalytic activity and cavity entrance size.

M96 contains one spherical cage A with a cavity-free diameter of $11 \AA$, an elongated cavity B with dimensions of $9.5 \times 12.6 \times 11.3$ $\AA$ and a narrow cavity $\mathrm{C}$ with dimensions of 3.6 x $4.5 \AA$ (Figure 3). ${ }^{15,16}$ Notably, these cavities are not connected to their own type, i.e., A-A, B-B and C-C connections were not observed. Cavities $\mathrm{B}$ and $\mathrm{C}$ are connected and the window between them of $\sim 4.5 \mathrm{x}$ $3.6 \AA$, while cavity $\mathrm{A}$ is not connected to $\mathrm{B}$ or $\mathrm{C}$ and is isolated. ${ }^{15,16}$ Thus, M96 has a zig-zag pore structure with connections between the B and C cavities (Figure 4). Only cavity $\mathrm{B}$ is accessible to PCB because it has a cavity entrance diameter of $4.6 \AA$, which is greater than the size of the PCB (Figure S5), while the entrances of the other cavities are smaller than PCB.

M100 contains tri-nuclear building blocks linked to each other via trimesate ligands with each corner corresponding to an $\mathrm{Al}$ trimer, and the faces covered by aromatic ligands. ${ }^{14}$ These supertetrahedrons then share corners to generate the 3D framework of the MOF, with two types of cavities, the first formed by 12 pentagonal windows $5.2 \AA$ across and the $2^{\text {nd }}$ cavity by 12 pentagonal and 4 hexagonal windows $8.8 \AA$ across (Figure $4 \mathrm{~d}) .{ }^{14}$ M100 possesses a much larger cavity entrance diameter of $6.4 \mathrm{~A}$ and $9.4 \AA$ for the pentagonal cage and the hexagonal cage, respectively (Figure 4f, g), making it more accessible to PCB. 


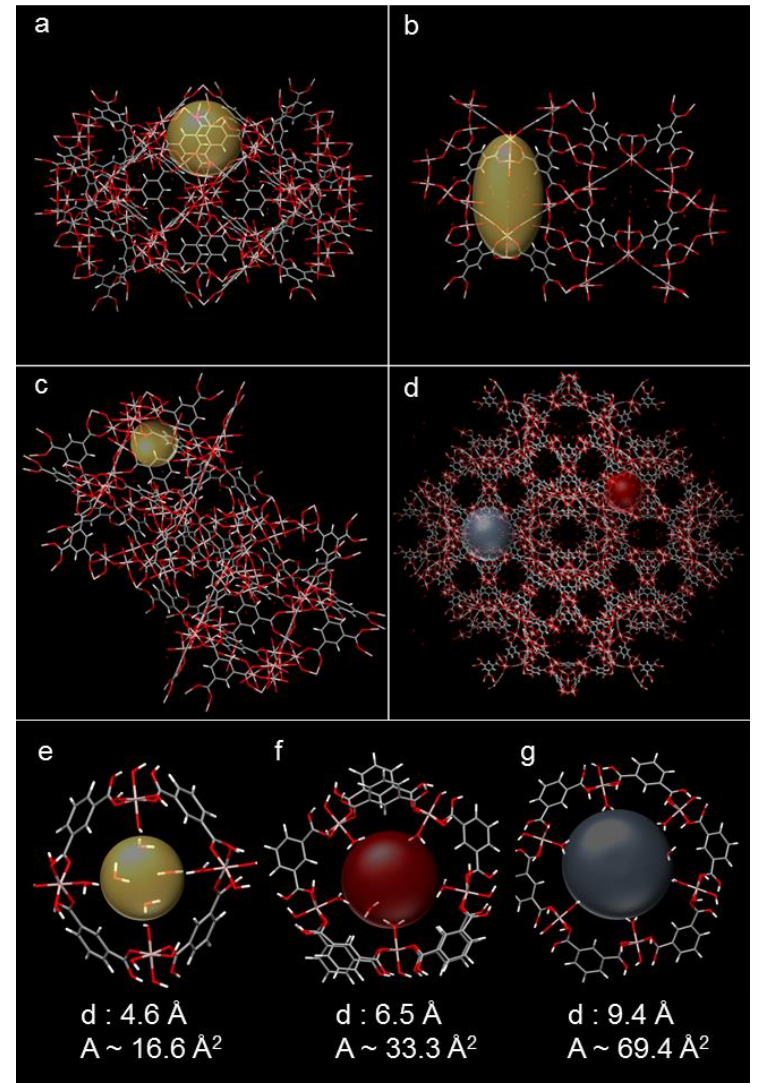

Figure 4. Framework structure of Al-MOFs (a,b,c) showing three different types of cavities in M96 and (d) two different types of cavities with pentagonal (red) and hexagonal (blue) cages in M100. Entrance size (d) and area of accessible cavities (A) of (e) M96 and (f,g) M100 AlMOFs.

The total area of the cavity entrance was estimated by knowing the area of the circled space inside the cavity entrance (Figure 4e$\mathrm{g}$ ), which will play a role in reactant/product diffusion inside/outside the cavity. M100 has cavity entrance areas of 33.3 $\AA^{2}$ and $69.4 \AA^{2}$ for pentagonal and hexagonal cavities, respectively, ${ }^{14}$ while M96 has $16.6 \AA^{2}$ for its only accessible cavity, cavity B. ${ }^{15,16}$ A PCB molecule fits tightly into the entrance path of M96 but can easily enter M100 due to its larger cavity entrance size and area. In addition to the cavity size data from framework structure analysis, the pore size distribution (size and total numbers) of these cavities provides further information (Figure 2). The deconvoluted HK pore size distribution (Figure 2a3-b3) quantifies the individual contributions of pore sizes towards the total numbers of pores of various sizes. M100 contains two types of pores, $5 \pm 1 \AA$ and $9.5 \pm 4 \AA$, attributed to the pentagonal cage (cavity A) and hexagonal cage (cavity B) respectively. M96 contains three different types of pores, in accordance with the framework structure, cavities A, B, and C. The pore size distribution (Figure 2a3-b3, Table S2) shows that M100 has more pores with dimensions higher than $5 \AA$ (needed for PCB diffusion inside the catalytic pocket), while M96 has fewer such pores. This result indicates that M100 has better accessibility than M96, which is also supported by the reactant size-dependent catalytic activity (Figure 3b)
Apart from the textural properties, Al sites in M100 and M96 also have differences in their chemical nature in terms of the bonding, connectivity and environment, which may affect their catalytic activity. The structure of M100 is composed of trinuclear octahedrally coordinated aluminum building blocks that are arranged in a tetrahedral fashion (Figure S3). ${ }^{14,17}$ The corners of these blocks are connected to each other via a benzene-1,3,5tricarboxylic acid (BTC, also known as trimesate) ligand to form a supertetrahedral structure that contains seven non-equivalent $\mathrm{Al}$ centres. Previous studies have suggested that the presence of $\mu_{3-}$ oxo groups, hydroxyl groups and water molecules (free and bonded) ensures the electroneutrality of the framework (i.e., $\left.\mathrm{Al}_{3} \mathrm{O}\left(\mathrm{H}_{2} \mathrm{O}\right)_{2}(\mathrm{OH})[\mathrm{btc}]_{2}\right) .{ }^{15,17}$ On the other hand, M96 consists of two distinct inorganic components. The first component consists of a trinuclear aluminum octahedral corner shared with a $\mu_{3}$-oxo group that is connected to a BTC ligand and water molecules (i.e., $\left.\mathrm{Al}_{12} \mathrm{O}(\mathrm{OH})_{18}\left(\mathrm{H}_{2} \mathrm{O}\right)_{3}\left(\mathrm{Al}_{2}(\mathrm{OH})_{4}\right)[\mathrm{btc}]_{6}\right)$ (Figure S4). ${ }^{15}$ The second inorganic component is a 2D network consisting of $\mathrm{AlO}_{2}(\mathrm{OH})_{4}$ and $\mathrm{AlO}_{4}(\mathrm{OH})_{2}$ octahedra with two crystallographically nonequivalent types of aluminum centres. These two inorganic blocks are connected via a BTC ligand. M96 also contains one additional non-equivalent $\mathrm{Al}$ centre due to distortion in the framework structure. ${ }^{15}$ Therefore, four non-equivalent $\mathrm{Al}$ centres are present in M96.

To probe the various $\mathrm{Al}$ sites in both the MOFs, ${ }^{27} \mathrm{Al}$ magic-anglespinning (MAS) nuclear magnetic resonance (NMR) studies were performed. ${ }^{18-21}$ For M100, the broad signal in the ${ }^{27} \mathrm{Al}$ NMR spectrum consists of three poorly resolved signals at 11 to -38 $\mathrm{ppm}$, corresponding to the seven crystallographically independent octahedral Al sites $\left(\mathrm{Al}^{3+}{ }_{6 \mathrm{c}}\right.$ ) (Figure 5). ${ }^{[18,19]}$ However, M96 exhibited a broad signal at approximately 19 to $-22 \mathrm{ppm}$, corresponding to the four non-equivalent $\mathrm{Al}$ centres $\left(\mathrm{Al}^{3+}{ }_{6 \mathrm{c}}\right)$. In both of these MOFs, aluminium is hexacoordinated $\left(\mathrm{Al}^{3+}{ }_{6 \mathrm{c}}\right)$, but with different environments as can be seen in the ${ }^{27} \mathrm{Al} \mathrm{NMR}$ spectrum which shows different shifts for M100 and M96 (Figure $5)$.

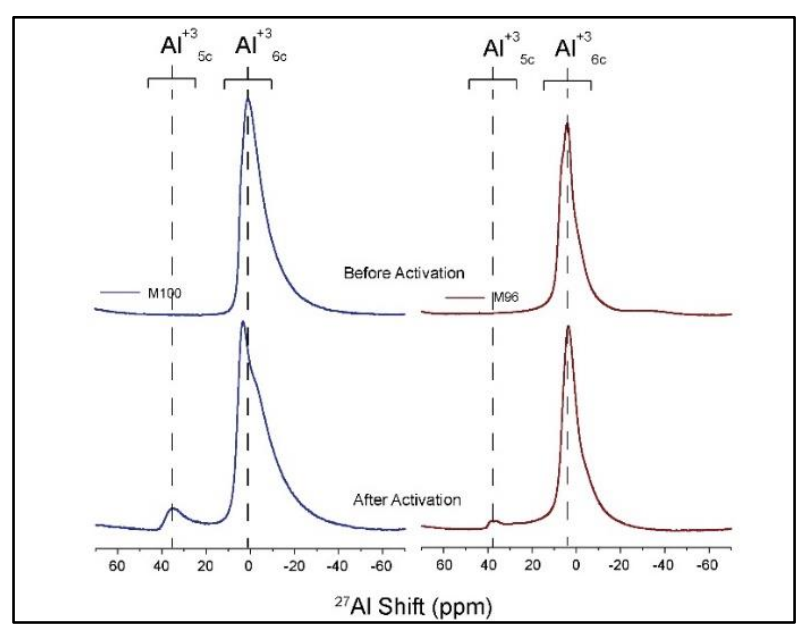

Figure 5. ${ }^{27} \mathrm{Al}$ solid-state MAS NMR spectra of Al-MOFs. 
After activation, the catalytic activity of M100 remained nearly the same, while the M96 exhibited slightly improved activity (Figure 3). This indicates that, during activation, surface active sites are generated in the M96 due to loss of the aquo species confirmed by the proton NMR (Figure S6), hence, reducing the coordination state of the aluminium centre and creating Lewis acidic pentacoordinated (5c) aluminium (i.e., coordinatively unsaturated sites (CUS) of aluminium $\left(\mathrm{Al}^{3+}{ }_{5 \mathrm{c}}\right) .{ }^{17,18}$ The generation of $\mathrm{Al}^{3+}{ }_{5 \mathrm{c}}$ was confirmed from the ${ }^{27} \mathrm{Al} \mathrm{NMR}$ spectrum of the $\mathrm{Al}-$ MOFs after activation. A new broad signal was seen at approximately 20 to $41 \mathrm{ppm}$ after activation (Figure 4), confirming the generation of CUS $\mathrm{Al}^{3+}{ }_{5 \mathrm{c}}{ }^{18}$ The number of $\mathrm{Al}(\mathrm{V})$ sites formed in M100 after activation was higher (5.2\%) as compared to M96 (2.8\%). The multiple-quantum MAS (MQMAS) ${ }^{27} \mathrm{Al}$ NMR spectrum of M96 showed four wellresolved signals (Figure 5), confirming four different crystallographic sites, Al1, Al2, Al3 and Al4. ${ }^{15,16}$ The deconvoluted ${ }^{27} \mathrm{Al}$ NMR $1 \mathrm{D}$ spectra (Figure S7) provided additional information regarding the various ${ }^{27} \mathrm{Al}$ sites and their local environments (quadrupolar coupling constants, $\mathrm{C}_{\mathrm{Q}}$ ) before and after activation process. The deconvolution was performed using Czjzek model ${ }^{22}$ and $\mathrm{C}_{\mathrm{Q}}$ values were extracted (Figure S8). Before the activation process, both the MOFs (M100 and M96) exhibit only $\mathrm{Al}(\mathrm{VI})$ sites and their $\mathrm{C}_{\mathrm{Q}}$ values are in the range of 0.004 to $0.009 \mathrm{MHz}$. These low $\mathrm{C}_{\mathrm{Q}}$ values before and after activation (Figure S8) indicate the symmetric environment of $\mathrm{Al}$ (VI) and $\mathrm{Al}(\mathrm{V})$ sites in both the MOFs. ${ }^{18,23,24}$ However, ${ }^{13} \mathrm{C}$ NMR studies of these MOFs before and after activation indicate that $\mathrm{T}_{2}$ values reduced after activation (Figure S9, Table S3). This decrease in the $T_{2}$ values can be correlated to the increase in the flexibility of the framework, ${ }^{25,26}$ due to the removal of water molecules from MOF crystal. The ${ }^{1} \mathrm{H}_{-}{ }^{27} \mathrm{Al}$ HETCOR studies (Figure S10) confirmed the removal of the water molecules, also seen in TGA (Fig. S2).

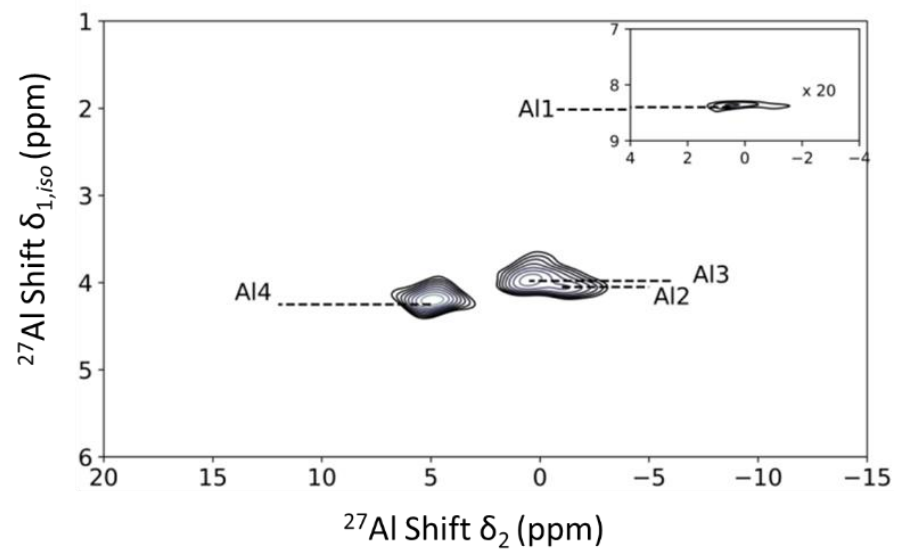

Figure 6. Two-dimensional triple-quantum MAS ${ }^{27} \mathrm{Al}$ NMR spectrum M96 (before activation) recorded on a $700 \mathrm{MHz}$ spectrometer using the split-t t$_{1}$-shifted-echo scheme.

The overall acidity of these MOFs was also affected by the activation step as reflected in the catalytic study (Figure 3). Lewis acidic $\mathrm{Al}^{3+}{ }_{5 \mathrm{c}}$ sites are generated only after activation, and, hence, before activation, Brønsted acidity is the only source of their acidity. However, after activation, the combination of Lewis and Brønsted acidic sites is responsible for their activity. It may be noted that $\mathrm{Al}^{3+}{ }_{5 \mathrm{c}}$ sites were also generated in the M100 (Figure 5), but still its catalytic performance decreased. This indicates the key role of the Brønsted acidity of these MOFs in their catalytic activity. The source of the Brønsted Acidity arises due to the water molecules directly coordinated to the Al sites. ${ }^{17,18}$ The elemental compositions of M100 and $\mathrm{M} 96$ are $\mathrm{Al}_{3} \mathrm{O}\left(\mathrm{H}_{2} \mathrm{O}\right)_{2}(\mathrm{OH})[\mathrm{btc}]_{2}$, and $\mathrm{Al}_{12} \mathrm{O}(\mathrm{OH})_{18}\left(\mathrm{H}_{2} \mathrm{O}\right)_{3}\left(\mathrm{Al}_{2}(\mathrm{OH})_{4}\right)[\mathrm{btc}]_{6}$ respectively, indicating the presence of more coordinating water in M100 than in M96 per aluminum. The activation process was performed under vacuum which removed $\mathrm{Al}$ coordinated water molecules (seen from TGA, Fig. S2), which reduces the total number of Brønsted acidic sites and as a result of it, the catalytic performance was reduced significantly (Figure 3).

To further understand this activation step, we performed MQMAS spectroscopy ${ }^{27,28}$ for M100 and M96. Their z-filtered ${ }^{27}$ Al MAS NMR spectra are shown in Figure 6 before and after activation. In these spectra, the position of the lines in the direct dimension corresponds to the direct-exciation ${ }^{27} \mathrm{Al}$ MAS NMR measurements, while isotropic resolution is obtained in the second dimension. In the spectrum of M100 before activation (Figure 7), strong signals due to $\mathrm{Al}^{3+}{ }_{6 c}$ sites are observed, but the seven crystallographically independent octahedral $\mathrm{Al}$ sites are not resolved. This finding indicates that $\mathrm{Al}^{3+}{ }_{6 \mathrm{c}}$ sites are in a very similar environment in M100, as seen in the comparably narrow signal in 1D NMR (Figure 5). However, in the case of M96, before activation, two strong signals originating from $\mathrm{Al}^{3+}{ }_{6 \mathrm{c}}$ sites are observed (Figure 7). This result indicates a more heterogeneous environment of the four non-equivalent $\mathrm{Al}$ centres of M96 Al MOFs, which was also observed in their 1D (Figure 5) and $2 \mathrm{D}$ triple-quantum $\mathrm{MAS}{ }^{27} \mathrm{Al}$ NMR spectrum (Figure 6). 


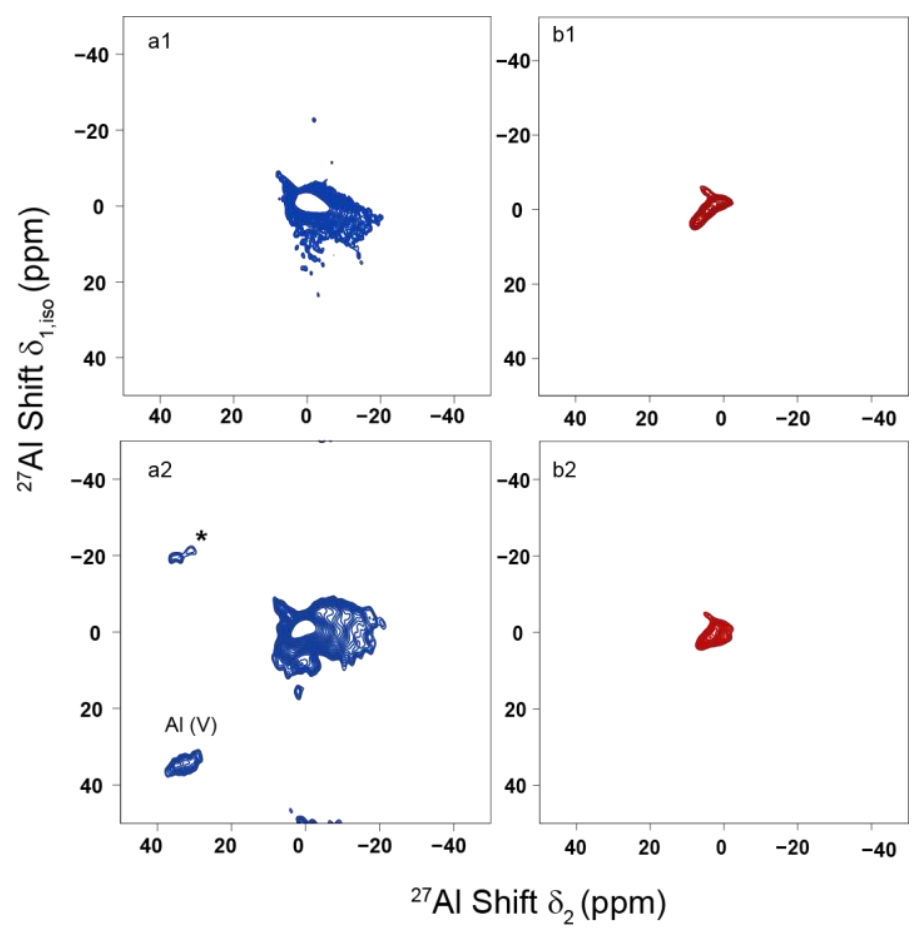

Figure 7. Two-dimensional triple-quantum MAS ${ }^{27} \mathrm{Al}$ NMR spectrum of (a1) M100, (b1) M96, before activation and (a2) M100, (b2) M96, after activation. The peak marked with * are the spinning sidebands. ${ }^{[28]}$

After the activation of these MOFs, in the case of M100, in addition to the signal for $\mathrm{Al}^{3+}{ }_{6 \mathrm{c}}$ sites, a signal for $\mathrm{Al}^{3+}{ }_{5 \mathrm{c}}$ sites around 35 ppm was observed (Figure 7). M96, after activation, did not show any signal for $\mathrm{Al}^{3+}{ }_{5 \mathrm{c}}$ sites, possibly due to their low abundance (as seen from 1D NMR, Figure 5). Another noticeable change that was observed in the MQMAS spectrum of M100 after activation was the broadening of the signal for $\mathrm{Al}^{3+}{ }_{6 \mathrm{c}}$ sites in both the direct and isotropic dimensions (Figure 7). This broadening indicates that these shifts became more dispersed due to the increase in the heterogeneity in the $\mathrm{Al}^{3+}{ }_{6 \mathrm{c}}$ environment after the loss of coordinated water molecules. This broadening was also observed in 1D NMR after activation (Figure 5). Interestingly, no such broadening was observed for M96 after activation, either in their MQMAS spectrum (Figure 7) or in their 1D spectrum (Figure 5). Instead, narrowing of the signal, with only one strong signal for $\mathrm{Al}^{3+}{ }_{6 \mathrm{c}}$, was observed, indicating a more homogeneous environment around $\mathrm{Al}$ after activation.

In conclusion, we found that the framework structure of Al-MOFs plays a critical role in determining their catalytic activity. The MOF with MIL-100 (Al) framework structure was catalytically active, while the same Al-MOF with MIL-96 (Al) framework structure showed poor catalytic activity. A detailed catalytic study, which was aided by crystal structure analysis and solidstate NMR studies, allowed us to explain this behavior. The sizes of the entrances to the cavities where active sites are located (catalytic pockets) play a crucial role. PCB molecules fit tightly into the entrance path of M96 but can easily enter M100 due to its larger cavity entrance size and area. M100 has more pores with dimensions higher than $5 \AA$ (needed for PCB diffusion into the catalytic pocket), while M-96 has fewer such pores. The higher catalytic activity of the M100 MOF compared to the M96 after activation was also due to the role of coordinated water molecules (Brønsted sites), and the coordination of $\mathrm{Al}$ sites (Lewis sites). Thus, this study contributes to the fundamental understanding of the catalytic nature of active sites in Al-MOFs, and this knowledge may be used to design MOFs with greater catalytic activity.

Supporting Information mentioned in the text accompanies this paper at doi:xxx.

\section{Acknowledgments}

This work was supported by the Department of Atomic Energy (DAE), Government of India. We also acknowledge EM, XRD facility of TIFR, Mumbai, Natioanl Facility for High-Field NMR, TIFR, Hyderabad and The Nottingham DNP MAS NMR Facility, funded by the University of Nottingham and EPSRC (EP/L022524/1).

\section{References}

1. Zhu, L.; Liu, X. -Q.; Jiang, H. -L.; Sun, L. -B. Metal-organic frameworks for heterogeneous basic catalysis. Chem. Rev. 2017, 117, 8129-8176.

2. García-García, P.; Müllera, M.; Corma, A. MOF catalysis in relation to their homogeneous counterparts and conventional solid catalysts. Chem. Sci. 2014, 5, 2979-3007.

3. Pascanu, V., Miera, G. G.; Inge, A. K.; Martín, B. Metal-Organic Frameworks as Catalysts for Organic Synthesis: A Critical Perspective. J. Am. Chem. Soc. 2019, 141, 7223-7234.

4. Yang, D.; Gates, B. C. Catalysis by Metal Organic Frameworks: Perspective and Suggestions for Future Research. ACS Catal. 2019, 9, 1779-1798.

5. Rosen, A. S.; Notestein, J. M.; Snurr, R. Q. Structure-Activity Relationships That Identify Metal-Organic Framework Catalysts for Methane Activation. ACS Catal. 2019, 9, 3576-3587.

6. Han, J.; Lee, M. S.; Thallapally, P. K.; Kim, M.; Jeong, N. Identification of Reaction Sites on Metal-Organic FrameworkBased Asymmetric Catalysts for Carbonyl-Ene Reactions. ACS Catal. 2019, 9, 3969-3977.

7. Zhang, X.; Huang, Z.; Ferrandon, M.; Yang, D.; Robison, L.; Li, P.; Wang, T. C.; Delferro, M.; Farha, O. K. Nature Catal. 2018, 1, 356362.

8. Ji, P.; Feng, X.; Oliveres, P.; Li, Z.; Murakami, A.; Wang, C.; Lin, W. Strongly Lewis Acidic Metal-Organic Frameworks for Continuous Flow Catalysis. J. Am. Chem. Soc. 2019, 141, 1487814888.

9. Maity, A.; Belgamwar, R. Polshettiwar, V. Facile Synthesis Protocol to Tune Size, Textural Properties \& Fiber Density of Dendritic Fibrous Nanosilica (DFNS): Applications in Catalysis and $\mathrm{CO}_{2}$ Capture. Nat. Prot. 2019, 14, 2177-2204.

10. Singh, B.; Mote, K. R.; Gopinath, C. S.; Madhu, P. K.; Polshettiwar, V. SBA-15-Oxynitrides as a Solid-Base Catalyst: Effect of Nitridation Temperature on Catalytic Activity. Angew. Chem. Int. Ed. 2015, 54, 5985-5989.

11. Dhiman, M.; Maity, A.; Das, A.; Belgamwar, R.; Chalke, B.; Lee, Y.; Sim, K.; Nam, J. M., Polshettiwar, V. . Plasmonic Colloidosomes of Black Gold for Solar Energy Harvesting and Hotspots Directed Catalysis for $\mathrm{CO}_{2}$ to Fuel Conversion. Chem. Sci. 2019, 10, 6694-6603.

12. Mishra, A. K.; Belgamwar, R.; Jana, R.; Datta, A.; Polshettiwar, V. Defects in Nanosilica Catalytically Convert CO2 to Methane without Any Metal and Ligand. Proc. Natl. Acad. Sci. U.S.A 2020, 117, 6383-6390.

13. Horcajada, P.; Serre, C.; Chang, J. -S.; Férey, G.; de la Peña-O'Shea, V. A.; Boissière, C.; Grosso, D.; Sanchez, C. Green microwave 
synthesis of MIL-100 (Al, Cr, Fe) nanoparticles for thin-film elaboration. Eur. J. Inorg. Chem. 2012, 5165-5174.

14. Volkringer, C.; Popov, D.; Loiseau, T.; Ferey, G.; Burghammer, M.; Riekel, C.; Haouas, M.; Taulelle, F. Synthesis, single-crystal X-ray microdiffraction, and NMR characterizations of the giant pore metal-organic framework aluminum trimesate MIL-100. Chem. Mater. 2009, 21, 5695-5697.

15. Loiseau, T.; Lecroq, L.; Volkringer, C.; Marrot, J.; Ferey, G.; Haouas, M.; Taulelle, F. Bourrelly, S.; Llewellyn, L. P. L.; Latroche, M. MIL-96, a porous aluminum trimesate 3D structure constructed from a hexagonal network of 18 -membered rings and $\mu 3$-oxocentered trinuclear units. J. Am. Chem. Soc. 2006, 128, 1022310230;

16. M. Benzaqui, R.S. Pillai, A. Sabetghadam, V. Benoit, P. Normand, J. Marrot, N. Menguy, D. Montero, W. Shepard, A. Tissot, C. Martineau-Corcos, C. Sicard, M. Mihaylov, F. Carn, I. Beurroeis, P.L. Llewellyn, G. De Weireld, K. Hadjiivanov, J. Gascon, F. Kapteijn, G. Maurin, N. Steunou, C. Serre. Revisiting the aluminum trimesate-based MOF (MIL-96): From structure determination to the processing of mixed matrix membranes for $\mathrm{CO}_{2}$ capture. Chem. Mater. 2017, 29, 10326-10338

17. Volkringer, C.; Leclerc, H.; Lavalley, J. -C.; Loiseau, T.; Férey, G.; Daturi, M.; Vimont, A. Infrared spectroscopy investigation of the acid sites in the metal-organic framework aluminum trimesate MIL100 (Al). J. Phys. Chem. C 2012, 116, 5710-5719.

18. Haouas, M.; Volkringer, C.; Loiseau, T.; Ferey, G.; Taulelle, F. Monitoring the activation process of the giant pore MIL-100 (Al) by solid state NMR. J. Phys. Chem. C 2011, 115, 17934-17944.

19. Volkringer, C.; Popov, D.; Loiseau, T.; Guillou, N.; Ferey, G.; Haouas, M.; Taulelle, F.; Mellot-Draznieks, C.; Burghammer, M.; Riekel, C. A microdiffraction set-up for nanoporous metal-organicframework-type solids. Nature Mat. 2007, 6, 760-764.

20. Wang, Z.; Jiang, Y.; Lafon, O.; Trebosc, J.; Kim , K. D.; Stampfl, C.; Baiker, A.; Amoureux, J. -P.; Huang, J. Brønsted acid sites based on penta-coordinated aluminum species. Nature Comm. 2016, 7, 13820.

21. Giovine, R.; Volkringer, C.; Trébosc, J.; Amoureux, J.-P.; Loiseau, T.; Lafon, O.; Pourpoint, F. NMR crystallography to probe the breathing effect of the MIL-53 (Al) metal-organic framework using solid-state NMR measurements of ${ }^{13} \mathrm{C}-{ }^{27} \mathrm{Al}$ distances. Acta Cryst. 2017, 73, 176-183.

22. d'Espinose de Lacaillerie, J; Fretigny, C.; Massiot, D. MAS NMR spectra of quadrupolar nuclei in disordered solids: the Czjzek model. J. Mag. Reson. 2008, 192, 244-251.

23. Wischert, R.; Florian, P.; Copéret, C.; Massiot, D.; Sautet, P. Visibility of Al Surface Sites of $\gamma$-Alumina: A Combined Computational and Experimental Point of View. J. Phys. Chem. C 2014, 118, 15292-15299.

24. Lam, E.; Vives, A.; Copéret, C. Role of Coordination Number, Geometry, and Local Disorder on ${ }^{27} \mathrm{Al}$ NMR Chemical Shifts and Quadrupolar Coupling Constants: Case Study with Aluminosilicates. J. Phys. Chem. C 2017, 121, 19946-19957.

25. Hoffmann, H. C.; Debowski, M.; Müller, P.; Paasch, S., Senkovska, I.; Kaskel, S.; Brunner, E. Solid-State NMR Spectroscopy of MetalOrganic Framework Compounds (MOFs). Materials 2012, 5, 25372572.

26. Dawson, D. M.; Jamieson, L. E.; Mohideen, M. I. H.; McKinlay, A. C.; Smellie, I. A.; Caou, R.; Keddie, N. S.; Morris, R. E.; Ashbrook, S. E. High-resolution solid-state ${ }^{13} \mathrm{C}$ NMR spectroscopy of the paramagnetic metal-organic frameworks, STAM-1 and HKUST-1 Phys. Chem. Chem. Phys. 2013, 15, 919-929.

27. Medek. A; Harwood J. S.; Frydman, L. Multiple-quantum magicangle spinning NMR: A New method for the study of quadrupolar nuclei in solids. J. Am. Chem. Soc. 1995, 117, 12779-12787.

28. Marinelli L.; Frydman, L. On the origin of spinning sidebands in MQMAS NMR experiments. Chem. Phy. Lett. 1997, 275, 188-198. 
ToC graphic

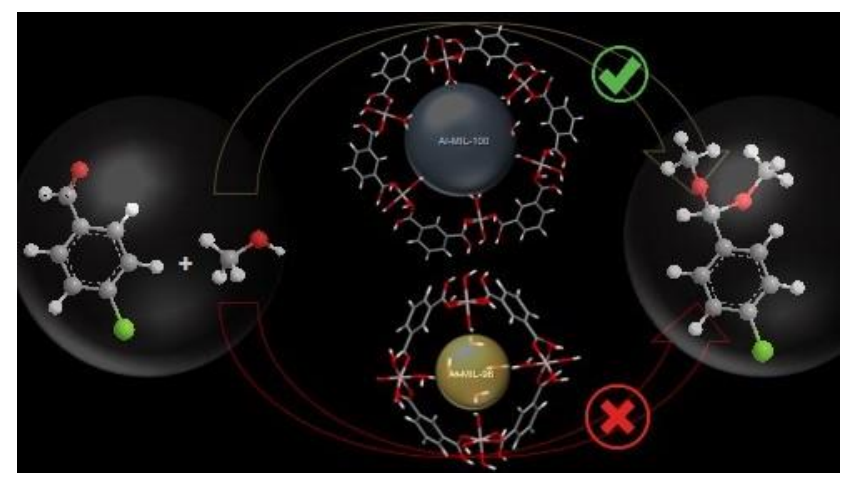

